\title{
Musik tradisi berkelanjutan untuk generasi muda Dayak
}

\section{Bahau}

\section{Bayu Arsiadhi Putra*, Jonathan Irene Sartika Dewi Max, \& Yofi Irvan Vivian}

Fakultas IImu Budaya, Universitas Mulawarman, Indonesia

*bayuarsiadhiputra@gmail.com

\begin{abstract}
Traditional music is an expression of hereditary culture that is owned by certain ethnic groups. The young Dayak Bahau generation is committed to preserving traditional music even though they have experienced modern life and live in big cities. However, conservation efforts are always carried out in monotonous ways, resulting in various obstacles that are beyond the control of this ethnic group. Therefore, it is necessary to carry out empowerment activities so that the maintenance and preservation of traditional music can be sustainable. An understanding of the dangers of traditional music extinction is needed, the factors causing extinction and maintenance strategies. This service provides training to the young Dayak Bahau generation in exploring challenges and opportunities for the sustainability of traditional music. Assistance is also carried out in revitalizing traditional arts that are threatened with extinction. This knowledge and skills make traditional music more preserved with an approach that emphasizes the decisions of traditional music owners.
\end{abstract}

\begin{abstract}
Abstrak Musik tradisi merupakan ekspresi budaya turun temurun yang dimiliki oleh kelompok etnis tertentu. Generasi muda Dayak Bahau berkomitmen untuk melestarikan musik tradisi meski pun telah mengalami kehidupan modern dan tinggal di kota besar. Namun upaya pelestarian selalu dilakukan dengan cara-cara yang monoton sehingga muncul berbagai hambatan yang berada di luar kendali kelompok etnis ini. Oleh karena itu, perlu dilakukan kegiatan pemberdayaan agar upaya pemeliharaan dan pelestarian musik tradisi dapat berkelanjutan. Diperlukan pemahaman tentang bahaya kepunahan musik tradisi, faktor-faktor penyebab kepunahan dan strategi pemeliharaan. Pengabdian ini memberikan pelatihan kepada generasi muda Dayak Bahau dalam mengeksplorasi tantangan dan peluang keberlanjutan musik tradisi. Pendampingan juga dilakukan dalam merevitalisasi seni tradisi yang mengalami ancaman kepunahan. Pengetahuan dan keterampilan ini membuat musik tradisi lebih terpelihara dengan pendekatan yang lebih menekankan keputusan para pemilik musik tradisi.
\end{abstract}

Keywords: traditional music; sustainability; Dayak Bahau; revitalization

\section{¿ OPEN ACCESS}

Citation: Putra, B.A., Max, J.I.S.D., \& Vivian, Y.I. (2020). Musik tradisi berkelanjutan untuk generasi muda Dayak bahau. Riau Journal of Empowerment, 3(3), 161-169. https://doi.org/10.31258/raje.3.3.161-169

Paper type: Community service

Received: 2020-07-10 Revised: 2020-09-05 Accepted: 2020-09-08

Language: Bahasa Indonesia (id)

Funding: Direktorat Riset dan Pengabdian Masyarakat, Direktorat Jenderal Penguatan Riset dan Pengembangan Kementerian Riset, Teknologi, dan Pendidikan Tinggi Republik Indonesia

ISSN 2623-1549 (online), 2654-4520 (print)

C 2020 Bayu Arsiadhi Putra, Jonathan Irene Sartika Dewi Max, \& Yofi Irvan Vivian. Author(s) retain the copyright of article published in this journal, with first publication rights granted to Riau Journal of Empowerment. The article is licenced under Creative Commons Attribution 4.0 International License. This license permits unrestricted use, distribution, and reproduction in any medium, provided the original author and source are credited 


\section{PENDAHULUAN}

Urgensi pelestarian ekspresi budaya menjadi perhatian dunia sejak dua dekade terakhir. Inisiasi terkemuka termuat dalam deklarasi dan konvensi United Nations Educational, Scientific and Cultural Organization (UNESCO), seperti Universal Declaration on Cultural Diversity (United Nations Educational, Scientific and Cultural Organization, 2001), Convention for the Safeguarding of Intangible Cultural Heritage (UNESCO, 2003), Convention on the Protection and Promotion of the Diversity of Cultural Expressions (UNESCO, 2005), dan The Declaration on the Rights of Indigenous People (United Nations High Commission for Human Rigths, 2008). Keempat dokumen tersebut sekaligus menggambarkan bahwa ekspresi budaya, termasuk praktik musik penduduk asli (indigenous people) berada dalam ancaman kepunahan.

Latar belakang yang sama mendorong program pelestarian musik tradisi di Indonesia. Pada tahun 2017, Kementerian Pendidikan dan Kebudayaan menetapkan 594 kesenian berbagai etnis sebagai Warisan Budaya TakBenda (Paluseri et al., 2018). Sebelum itu, banyak instansi di daerah secara berkala mencatat dan menginventarisasi ragam musik 'pribumi' yang berada dalam otoritas wilayahnya masing-masing. Meskipun mampu meningkatkan kesadaran khalayak luas akan adanya ancaman kepunahan, namun program yang umumnya diinisiasi oleh pemerintah ini cenderung melihat praktik musik tradisi sebagai artefak yang harus segera 'diawetkan' ke dalam bentuk catatan ketimbang dipandang sebagai praktik yang 'hidup' dalam suatu masyarakat.

Howard (2012) mengatakan "pelestarian budaya harus dinamis". Makna dinamis dapat berarti diperkaya sesuai keadaan saat ini, yang hasilnya ditransmisikan kepada generasi mendatang (Boyu et al., 2015). Schippers dan Grant (2016) bahkan tidak terlalu ambisius dalam menerjemahkan berkelanjutan, merupakan kondisi-kondisi yang dianggap layak bagi musisi, komunitas dan stakeholder dalam melestarikan musik tradisi. Sejalan dengan hal-hal tersebut, maka penting untuk mempertimbangkan bahwa perubahan dan ancaman kepunahan musik tradisi adalah hal yang paling dirasakan oleh masyarakat pemiliknya. Upaya proaktif akan lebih efektif jika melibatkan komunitas penduduk asli yang masih memelihara seni tradisi leluhur di masa sekarang. Sebagai tambahan, penduduk asli saat ini bukan lagi kelompok masyarakat yang tinggal di wilayah terisolir, karena itu tidak lepas dari pengaruh kapitalisme, ideologi dan kekuasaan. Banyak komunitas asli telah menetap di wilayah perkotaan, namun masih mempromosikan gagasan-gagasan para pendahulu mereka.

Suku Dayak Bahau merupakan salah satu penduduk asli yang mendiami Kota Samarinda. Mereka biasa disebut dengan masyarakat Bahau. Kebanyakan masyarakat Bahau adalah pendatang dari berbagai daerah di Kabupaten Mahakam Hulu (Mahulu), sebuah wilayah yang sering diasosiasikan sebagai 'pedalaman' Kalimantan. Masyarakat Bahau ke Samarinda umumnya didominasi oleh anak-anak muda yang ingin menempuh pendidikan di jenjang perguruan tinggi. Di Samarinda, komitmen generasi muda Bahau untuk melestarikan seni tradisi Bahau sangat tinggi. Hal ini dibuktikan dengan didirikannya beberapa sanggar seni khas Bahau. Peran mereka menjadikan seni-seni tradisi Bahau semakin dikenal, bahkan hingga ke manca negara.

Namun, tidak semua kesenian Bahau dapat kuat di tengah perkembangan zaman. Terdapat kesenian khas Bahau yang sudah jarang dipraktikkan. Salah satunya adalah musik sape karaang. Jueng, budayawan Bahau menyebutkan sape karaang sebagai produk budaya lama telah memasuki tahap mengkhawatirkan (2014). Bagi masyarakat Bahau, musik sape karaang 
tidak hanya sekedar permainan alat musik dan tari, tetapi juga mengandung nilai-nilai luhur budaya Bahau. Grant (2015) percaya bahwa lagu-lagu yang telah mengakar kuat dalam suatu kebudayaan adalah media penting dalam mentransmisikan pengetahuan tentang alam, pengobatan, mitos, larangan atau norma sosial. Dengan demikian, hilangnya musik tradisi berarti hilang juga kemampuan generasi mendatang untuk beradaptasi dengan perubahan yang tidak terduga (Marett, 2010).

Meskipun musik muncul dan menghilang seiring perubahan selera dan keadaan, tetapi beberapa "musik minoritas" dipaksa "menghilang" oleh faktor-faktor non musikal (Seeger dalam Schippers \& Grant, 2016). Hegemoni musik pop adalah faktor utama dalam mempersempit ruang gerak musik tradisi (Chan et al., 2017). Pendistribusian musik tradisi di internet menimbulkan masalah terkait hak kepemilikan (Martini, 2014). Selain itu terdapat faktor-faktor yang datang dari masyarakatnya sendiri, seperti perubahan cara hidup perdesaan ke cara hidup urban (Grant, 2012), rendahnya kebanggaan terhadap kebudayaan sendiri (Putra, 2018), dan minimnya proses pewarisan (Irawati, 2016). Mengingat banyaknya faktor berpengaruh terhadap keberlanjutan musik tradisi, maka pelestarian sebaiknya tidak hanya terbatas pada aktivitas memelihara keindahan bentuk dan struktur suara, tapi juga mempertimbangkan jejaring faktor non musikal kompleks yang sedang berperan.

Sebagaimana telah dikemukakan sebelumnya, program-program pelestarian musik tradisi jarang mengedepankan koneksi dengan masyarakat pemiliknya. Sebaliknya, kegiatan pengabdian ini akan melibatkan komunitas penduduk asli sebagai pemilik musik tradisi dengan lebih menekankan pengambilan keputusan dan tindakan yang sesuai dengan keinginan mereka. Oleh sebab itu, kegiatan pengabdian ini dimulai dengan memberikan pelatihan kepada generasi muda Dayak Bahau dalam memahami faktor-faktor yang berkontribusi terhadap keberlanjutan musik tradisi. Melalui pelatihan ini, diharapkan para generasi muda Bahau memiliki alternatif dan strategi dalam menjaga keberlanjutan musik warisan leluhur mereka.

\section{METODE PENERAPAN}

Pengabdian ini bertujuan menjawab permasalahan mitra atau generasi muda Dayak Bahau atas ancaman kepunahan musik tradisi berjenis sape karaang. Setelah permasalahan tersebut didiskusikan antara tim pengabdian dengan mitra, maka disepakati cara-cara untuk mengatasinya, yaitu melalui transfer pengetahuan tentang cara mengeksplorasi faktor-faktor yang berkontribusi terhadap keberlanjutan musik tradisi. Strategi pengabdian menggunakan pendekatan etnomusikologi terapan, yaitu memberdayakan komunitas budaya agar melakukan perubahan terencana melalui pengetahuan etnomusikologi (Pettan, 2015). Pengetahuan etnomusikologi terkait dengan model strategis dan teknik konservasi musik tradisi yang diberikan kepada generasi muda Dayak Bahau (Harrison, 2012).

\section{Sosialisasi Program}

Sosialisasi dilakukan dengan menghadirkan mitra dalam sebuah pertemuan, pada kesempatan tersebut disampaikan informasi tentang kegiatan yang akan dilaksanakan, keterlibatan mitra, tujuan, sumber pendanaan dan luaran yang akan dicapai. Dalam sosialisasi juga disampaikan mengenai pentingnya menjaga warisan budaya musik, dan konsekuensi-konsekuensi yang muncul ketika musik tradisi menghilang. 


\section{Pelatihan Pengetahuan Musik Tradisi Berkelanjutan}

Melalui pelatihan ini diharapkan mitra memiliki pengetahuan tentang pemeliharaan musik tradisi yang tidak hanya terbatas pada pengembangan struktur dan bentuk musik. Pengetahuan musik tradisi berkelanjutan merupakan sebuah model untuk mengevaluasi keberlanjutan dan ketahanan musik tradisi melalui lima faktor meliputi: (a) belajar dan pembelajaran; (b) musisi dan komunitas; (c) konteks dan konstruk; (d) infrastruktur dan regulasi; (e) media dan industri musik.

Faktor belajar dan pembelajaran musik dipergunakan untuk memahami kesamaan dan perbedaan antara pelatihan formal dan nonformal, musik tradisi berbasis notasi dan transmisi langsung, pembelajaran dari guru tradisi atau melalui website. Sub-sub faktor tersebut akan dikoneksikan dengan filosofi masing-masing pengajar dan pembelajar.

Faktor musisi dan komunitas fokus terhadap peran dan posisi musisi dalam komunitas. Secara lebih mendalam, mitra akan mempelajari tentang aspek kreatif musisi yang dipengaruhi oleh teknologi, media, filosofi, perjalanan, pengajaran, remunerasi, dukungan komunitas, karir, dan aktivitas non musikal, serta sikap komunitas dan masyarakat terhadap praktik musik tradisi.

Faktor konteks dan konstruk. Faktor ini sebagai pedoman untuk mengeksplorasi konteks sosial dan konteks budaya suatu praktik musik tradisi. Melalui faktor ini mitra akan mendapat pengetahuan lebih mendalam mengenai pengaruh akulturasi budaya, isu keaslian, estetika, identitas, gender, selera musikal, praduga, rasisme dan isu perampasan atau apropriasi budaya.

Faktor infrastruktur dan regulasi. faktor ini terkait hal-hal bersifat ekstra musikal. Misalnya, sarana pertunjukan, latihan dan pembelajaran musik tradisi. Begitu pula dengan ketersediaan instrumen musik. Faktor ini juga membantu memahami sejauh mana kebijakan, hak cipta, dan undang-undang yang membatasi ekspresi artistik para musisi.

Faktor terakhir adalah media dan industri musik. Faktor ini mengarah kepada diseminasi dan promosi musik meliputi rekaman, radio, televisi dan internet. Selain itu, mengkaji lebih dalam tentang peran dan keterlibatan penonton, patron, sponsor, pemerintah, yang lebih mengarah kepada seni sebagai 'produk komodifikasi'. Dengan menganalisis isu spesifik dari setiap faktor, maka dapat menilai bagaimana suatu genre musik menghilang atau bertambah kuat, sehingga dapat menginformasikan strategi terbaik untuk meningkatkan keberlanjutan musik tradisi.

Dalam pengaplikasiannya, pertanyaan dari setiap faktor akan didiskusikan dengan peserta. Melalui pertanyaan tersebut, peserta didorong untuk menentukan faktor pendukung maupun penghambat keberlanjutan musik tradisi berdasarkan pengalaman mereka selama berkesenian. Selanjutnya, beberapa pelestarian budaya musik yang sukses dengan latar belakang persoalan sama akan diberikan sebagai bahan pertimbangan untuk melakukan pelestarian. Pelatihan dilakukan selama beberapa kali guna memastikan informasi yang disampaikan terserap dan dapat diterapkan dengan baik.

\section{Perekaman Video Pertunjukan Musik Tradisi}

Tahapan ini merupakan pendampingan kepada peserta untuk membuat video aktivitas bermain musik sape karaang. Tujuan perekaman adalah menghasilkan luaran video dan audio pertunjukan musik tradisi Bahau dengan kualitas baik. Sebelum pelaksanaan perekaman, mitra dan tim pengabdian menyusun daftar frame yang akan diambil beserta teknik pengambilan 
gambar yang digunakan. Semua hal tersebut tertulis dalam sebuah daftar yang akan dibawa dalam pelaksanaan perekaman di lapangan. Selain itu, video pertunjukan akan disisipkan narasi tentang penghambat dan pendukung keberlanjutan musik sape karaang, yang merupakan hasil analisis mitra dari pelatihan sebelumnya.

\section{Evaluasi}

Evaluasi dilaksanakan dengan beberapa cara. Pertama melalui pengadaan tes di awal dan akhir pelatihan. Penilaian ini digunakan untuk melihat sejauh mana pemahaman individu dalam menyerap materi pelatihan musik tradisi berkelanjutan. Evaluasi selanjutnya adalah menilai luaran video yang merupakan hasil pengeditan mitra secara berkelompok. Pengamatan dan wawancara juga dilakukan selama kegiatan untuk menilai partisipasi mitra dan mendapatkan proyeksi ke depan yang direncanakan mitra berdasarkan pengetahuan yang telah diberikan.

\section{HASIL DAN KETERCAPAIAN SASARAN}

\section{Pelatihan Musik Tradisi Berkelanjutan}

Pelatihan Musik Tradisi Berkelanjutan dilaksanakan di Kampus Fakultas Ilmu Budaya, Universitas Mulawarman, yang dihadiri 8 orang kalangan muda etnik Dayak Bahau dari Sanggar Seni Apo Lagaan. Pada tahap ini presentasi mengenai model musik tradisi berkelanjutan diberikan. Mitra dikenalkan tentang faktor-faktor yang menyebabkan kehilangan seni tradisi, dan metode menganalisis faktor-faktor tersebut. Dalam pelaksanaannya, kombinasi metode ceramah dengan penggunaan media, tanya-jawab, dan selingan mempraktikkan musik tari tradisi Bahau dilakukan agar mengurangi perasaan jenuh yang dialami mitra.

Dalam tahap diskusi, mitra membentuk sebuah kelompok yang akan bekerja membahas pertanyaan-pertanyaan yang telah disiapkan tim pengabdian. Mitra merasa pertanyaanpertanyaan tersebut secara nyata dekat dengan pengalaman mereka saat berkesenian. Misalnya, saat sedang membahas salah satu faktor pewarisan sape karang yang telah berubah. Dahulu, sape karaang hanya diajarkan oleh orang-orang tua di Kampung Mahakam Hulu, kini peran orang tua untuk mengajarkan sape karaang semakin berkurang. Oleh karena itu, generasi muda Bahau di Samarinda mencari upaya lain seperti belajar dari internet. Bagi mereka, kenyataan tersebut bisa berupa ancaman sekaligus peluang. Keseriusan mitra dalam mengikuti diskusi bersama terlihat sebagaimana pada Gambar 1. 


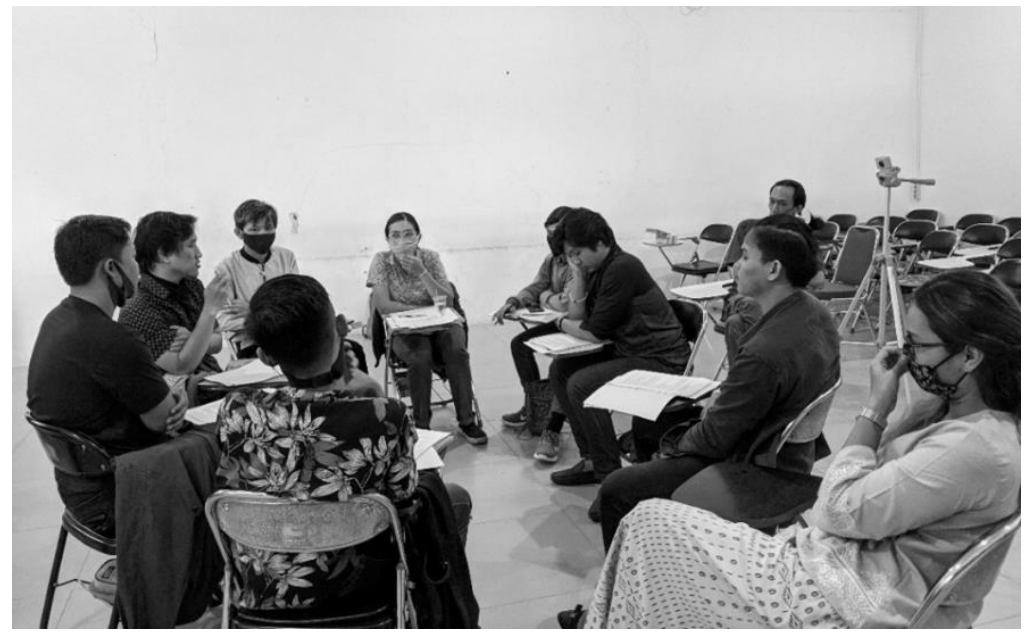

Gambar 1. Suasana diskusi peserta

Pelaksaan diskusi untuk membahas faktor-faktor keberlanjutan musik tradisi menjadikan mitra lebih kritis. Salah satu analisis kritis mitra yang didasarkan faktor belajar dan pembelajaran musik tradisi adalah keberadaan institusi atau perguruan tinggi seni yang menawarkan program studi musik tradisi. Mitra mengkhawatirkan jika kehadiran institusi seni justru mengaburkan tatanan seni tradisi mereka. Mitra pernah melihat pertunjukan sape karaang yang dibawakan oleh mahasiswa seni, tetapi dimainkan tidak sesuai dengan normanorma kebudayaan Bahau.

Hasil analisis peserta terhadap faktor belajar dan pembelajaran menjadi landasan untuk melakukan tahap perekaman pertunjukan sape karaang. Hasil analisis tersebut dikembangkan ke dalam bentuk teks yang dinarasikan peserta untuk kebutuhan salah satu frame di video. Perekaman video pertunjukan musik tradisi sape karaang dilakukan di tempat berbeda agar mendapatkan kualitas pencahayaan maksimal dan suasana representatif. Pelaksanaan perekaman pertunjukan sape karaang dan perekaman frame pembacaan teks narasi penghambat keberlanjutan sape karaang dapat dilihat pada Gambar 2.

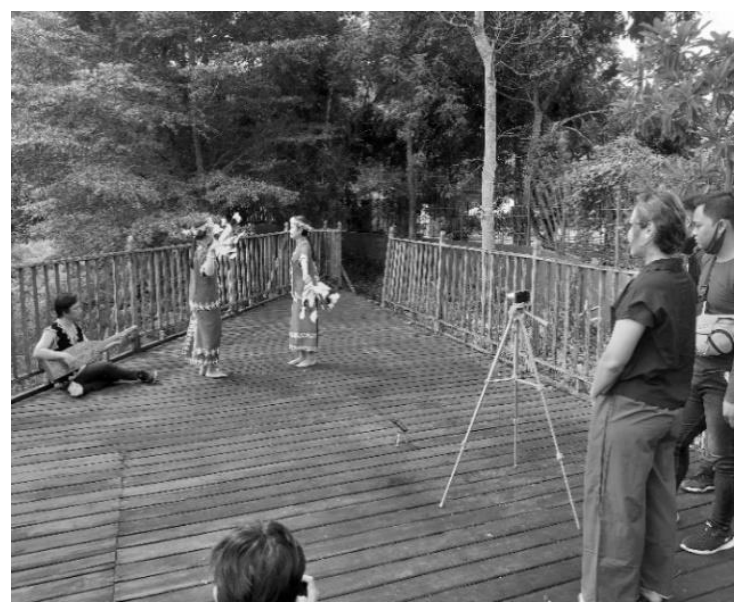

(a)

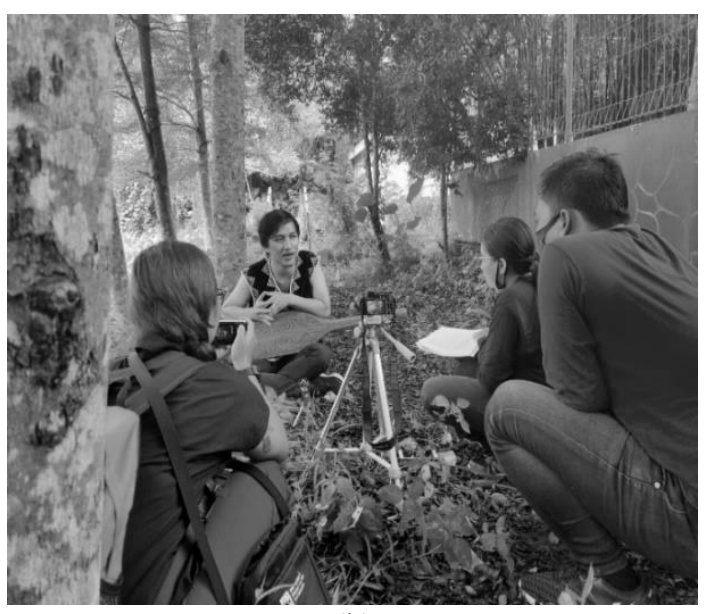

(b)

Gambar 2. Merekam (a) pertunjukan dan (b) narasi penghambat keberlanjutan sape karaang

\section{Evaluasi Kegiatan}

Evaluasi kegiatan berdasarkan kuis yang diberikan di awal dan akhir pengabdian secara umum menunjukkan peningkatan pengetahuan. Hasil rata-rata pre-test peserta yaitu dari nilai 56,2 
mengalami peningkatan pada post-test menjadi bernilai 75 . Selain itu peserta juga telah mampu menyelesaikan proses editing video dan mengunggahnya ke kanal YouTube (Sanggar Seni Apo Lagaan, 2020). Karya video peserta dapat dilihat pada Gambar 3. Sementara berdasarkan wawancara, tim mendapatkan harapan peserta yang akan membawa materi pelatihan ini untuk dibahas dalam pertemuan rutin di sanggar seni mereka.

Tabel 1. Skor awal dan akhir peserta

\begin{tabular}{ccc}
\hline & \multicolumn{2}{c}{ Nilai } \\
\cline { 2 - 3 } Peserta & Awal & Akhir \\
\hline Peserta 1 & 60 & 90 \\
Peserta 2 & 50 & 60 \\
Peserta 3 & 60 & 90 \\
Peserta 4 & 40 & 60 \\
Peserta 5 & 80 & 80 \\
Peserta 6 & 50 & 70 \\
Peserta 7 & 50 & 70 \\
Peserta 8 & 60 & 80 \\
Rata-rata & 56,2 & 75 \\
\hline
\end{tabular}

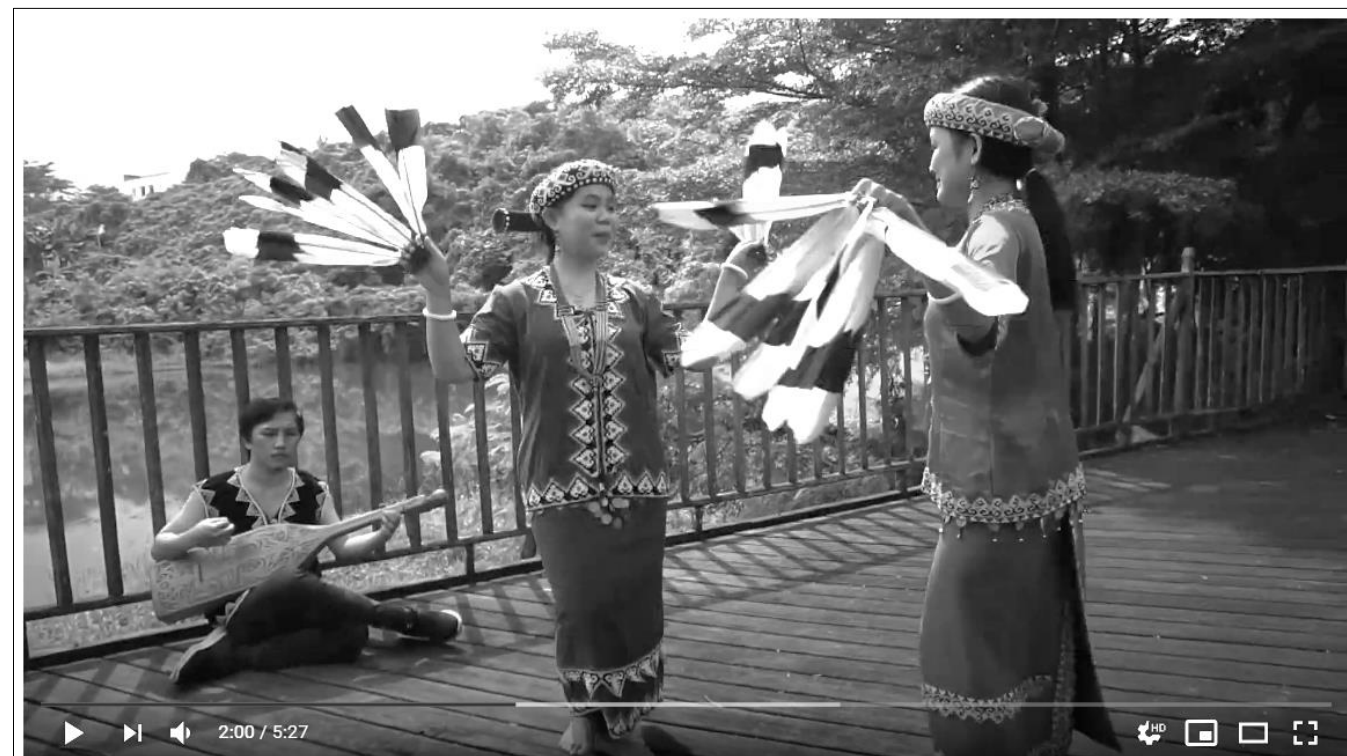

Sapeq Karaang (Sapeq Dayak Bahau)

101 views $\cdot \operatorname{Sep} 3,2020$

S Sanggar Seni Apo Lagaan

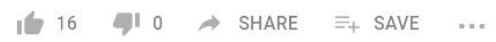

Gambar 3. Tampilan video yang dibuat peserta (Sanggar Seni Apo Lagaan, 2020)

Model musik tradisi berkelanjutan merupakan suatu pendekatan agar dapat membaca keberlanjutan musik tradisi, yang didasarkan atas keterangan dari masa dahulu, sekarang dan harapan untuk masa yang akan datang. Pendekatan seperti ini dapat dikatakan lebih dinamis ketimbang hanya memuseumkan musik tradisi ke dalam bentuk pencatatan atau inventarisasi. 
Model pelestarian seperti ini sangat membutuhkan keterlibatan komunitas asli sebagai pemilik kebudayaan, sehingga mereka dapat belajar cara penggunaannya dan memperbarui budaya mereka sendiri dengan cara mereka sendiri.

\section{KESIMPULAN}

Pelatihan musik tradisi berkelanjutan sebagai upaya pelestarian dan pemeliharaan musik tradisi sangat berdampak terhadap kemampuan peserta dalam mengidentifikasi dan menganalisis ancaman kepunahan musik tradisi. Peningkatan pemahaman peserta tampak pada konsep-konsep yang diberikan sebagaimana ditunjukkan dengan adanya perbedaan antara nilai pre-test dan post-test. Pemikiran kritis peserta juga muncul seperti dituangkan dalam narasi di video yang mengkhawatirkan lemahnya proses pewarisan dalam budaya sendiri dan keberadaan institusi formal seni yang cenderung mengaburkan nilai-nilai budaya mereka.

Secara umum dapat dikatakan jika kegiatan ini telah berhasil menerapkan alternatif baru mengenai teknik konservasi musik tradisi. Pemeliharaan musik tradisi tidak lagi hanya sebatas memfokuskan pengembangan bentuk dan struktur suara tetapi juga dapat dilakukan dengan cara mengasah kapasitas intelektual masyarakat pemilik seni tradisi melalui analisis berbagai faktor yang berkontribusi terhadap keberlanjutan musik tradisi.

Terlepas dari fokus pengabdian ini pendampingan lebih lanjut tentu sangat diperlukan. Terutama ketika mendiskusikan faktor-faktor keberlanjutan musik tradisi dapat melibatkan stakeholder, tokoh adat dan pemerintah yang berurusan dalam bidang pelestarian budaya. Begitu pula dengan implementasi hasil analisis sebaiknya tidak melulu ke dalam format video dan audio. Diperlukan tindakan lebih nyata seperti mendorong melakukan perbaikan pada faktor-faktor yang menghambat keberlanjutan praktik musik tradisi.

\section{UCAPAN TERIMA KASIH}

Terima kasih penulis ucapkan kepada Direktorat Riset dan Pengabdian Masyarakat, Direktorat Jenderal Penguatan Riset dan Pengembangan Kementerian Riset, Teknologi, dan Pendidikan Tinggi Republik Indonesia yang telah mendanai penelitian ini. Penulis juga mengucapkan terima kasih kepada Lembaga Penelitian dan Pengabdian kepada Masyarakat Universitas Mulawarman yang telah memberikan asistensi selama kegiatan pengabdian.

\section{Daftar Pustaka}

1. Boyu, Z., Hui, Y., \& Schippers, H. (2015). Report: The Rise and Implementation of Intangible Cultural Heritage Protection for Music in China. The World of Music, 4(1), 45-59.

http://www.jstor.org/stable/43561466

2. Chan, C.S.C., \& Saidon, Z.L. (2017). Advocating Contemporary Traditional Indigeneous Semai Music Through an Exploration of Youth Interest. International Journal of Academic Research in Business and Social Sciences, 7(7), 440-449. https:// doi.org/10.6007/IJARBSS/v7-i7/3114

3. Grant, C. (2012). Rethinking Safeguarding: Objections and Responses to Protecting and Promoting Endangered Musical Heritage. Ethnomusicology, 21(1), 39-59. https://doi.org/10.1080/17411912.2012.641733

4. Grant, C. (2015). Music Endangerment as a Wicked Problem. International Journal of Heritage Studies, 21(7), 629-641. https://doi.org/10.1080/13527258.2014.976245 
5. Harrison, K. (2012). Epistemologies of Applied Ethnomusicology. Ethnomusicology, 56(3), 505529. https://doi.org/10.5406/ethnomusicology.56.3.0505

6. Howard, K. (2012). Music as Intangible Cultural Heritage: Policy, Ideology and Practice in the Preservation of East-Asian Tradition. Ashgate.

7. Irawati, E. (2016). Transmisi Kelentangan dalam Masyarakat Dayak Benuaq. Resital, 17(1), 118. https://doi.org/10.24821/resital.v17i1.1686

8. Jueng, A. (2014, Mei 3). Sape' Karaang (bagian I). https://damaibumi.com/2017/05/03/sapekaraang-bagian-i/.

9. Marett, A. (2010). Vanishing Songs: How Musical Extinctions Threaten the Planet. Ethnomusicology, 19(2), 249-262. https://doi.org/10.1080/17411912.2010.508238

10. Martini, D. (2014). The Fulfillment of Economic and Moral Rights of Indigenous Peoples on Traditional Knowledge and Traditional Cultural Expressions Through Indonesia's TPR's System. Jurnal IUS Kajian Hukum dan Keadilan, 2(3), 455-475. http://jurnalius.ac.id/ojs/index.php/jurnalIUS/article/view/181

11. Paluseri, D.D., Putra, S.A., Hutama, H.S., \& Fajri, M. (2018). Penetapan Warisan Budaya TakBenda Indonesia 2017. Direktorat Warisan dan Diplomasi Budaya Direktorat Jenderal Kebudayaan Kementerian Pendidikan dan Kebudayaan

12. Pettan, S. (2015). Applied Ethnomusicology in the Global Arena. In S. Pettan, \& J.T. Titon (Eds.), The Oxford Handbook of Applied Ethnomusicology (pp. 29-52). Oxford University Press.

13. Putra, B.A. (2018). Tantangan Keberlanjutan Musik Tingkilan di Kutai Kartanegara [Conference presentation]. Seminar Antar Bangsa: Seni Budaya dan Desain.

http://seminarsedesa.um.ac.id/wp-content/uploads/2018/10/24-tantangan-keberlanjutanTingkilan-di-Kutai-Kartanegara1.pdf

14. Sanggar Seni Apo Lagaan. (2020, September 3). Sapeq Karaang (Sapeq Dayak Bahau) [Video]. YouTube. https://youtu.be/WEoHDOSHqII

15. Schippers, H., \& Grant, C. (2016) Sustainable Future for Music Cultures: An Ecological Perspective. Oxford University Press.

16. United Nations Educational, Scientific and Cultural Organization. (2001, November 2). Declaration on the Promotion of Cultural Diversity. http://portal.unesco.org/en/ev.phpURL_ID=13179\&URL_DO=DO_TOPIC\&URL_SECTION=201.html.

17. United Nations Educational, Scientific and Cultural Organization. (2003, October). Convention for the Safeguarding of Intangible Cultural Heritage. http://www.unesco.org/culture/ich/index.php?pg=00006

18. United Nations Educational, Scientific and Cultural Organization. (2005, October 20). Convention on the Protection and Promotion of the Diversity of Cultural Expressions. http://portal.unesco.org/en/ev.php$\underline{\text { URL_ID }=31038 \& U R L \_D O=D O \_T O P I C \& U R L \_S E C T I O N=201 . h t m l}$

19. United Nations High Commission for Human Rigths. (2008). Declaration on the Rights of Indigenous Peoples. United Nations. http://www.un.org/esa/socdev/unpfii/documents/DRIPS_en.pdf 